\title{
Anionic Polymerizations of 1-(2-Methoxyphenyl)-1,3-butadiene and 1-(4-Methoxyphenyl)-1,3-butadiene -Microstructures of Polymers and Characterizations of Living Anion Chain Ends-
}

\author{
Yasushi Tsuji, Toshimitsu Suzuki, Yoshihisa WATANABE, \\ and Yoshinobu TAKEGAMI \\ Department of Hydrocarbon Chemistry, Faculty of Engineering, Kyoto University, \\ Yoshida, Sakyo-ku, Kyoto 606, Japan.
}

(Received November 15, 1980)

\begin{abstract}
Anionic polymerizations of trans-1-(2-methoxyphenyl)-1,3-butadiene (o-MeO-1PB) and trans-1-(4-methoxyphenyl)-1,3-butadiene ( $p$-MeO-1-PB) were carried out with $t$-BuLi. Poly $(p$-MeO-1-PB) obtained in THF has a microstructure similar to poly(1-phenyl-1,3-butadiene) prepared under the same condition; trans-1,4 $78-79 \%$, cis-1,4 $11-12 \%$, and $3,410 \%$. Poly $(p$ MeO-1-PB) obtained in toluene or benzene has a 3,4 structure (more than $98 \%$ ) with cyclization. On the other hand, poly $(o-\mathrm{MeO}-1-\mathrm{PB})$ obtained in THF or toluene has 3,4 structure (more than $98 \%)$. Poly $(o-\mathrm{MeO}-1-\mathrm{PB})$ prepared in toluene, however contains a considerable number of cyclized structures. The characterization of the living anion chain ends of oligomeric $p-\mathrm{MeO}-1-\mathrm{PB}$ and $o$ MeO-1-PB shows that the electron releasing effect of the methoxy substituents does not affect the microstructures of the resulting polymers. The microstructures are determined by the aggregated structures of the chain ends or the steric hindrance caused by the ortho methoxy group.

KEY WORDS 1-(2-Methoxyphenyl)-1,3-butadiene / 1-(4-Methoxyphenyl)1,3-butadiene / Anionic Polymerization / Microstructure / Carbon 13 NMR/ Living Oligomer / Charge Distribution / Steric Effect / Aggregation / Polymerization Mechanism /
\end{abstract}

We have recently investigated the microstructures of poly(1-phenyl-1,3-butadiene) [poly(1-PB) $]^{1}$ and poly(2-phenyl-1-3-butadiene) [poly(2-PB)] ${ }^{2}$ prepared by anionic polymerization, and further characterized the living anion chain ends of the oligomers. $^{3,4}$

Poly(1-PB) obtained in THF with anionic initiators contains mainly trans-1,4 structure (78$84 \%$ ), whereas in the polymers prepared in hydrocarbon solvents, cis-1,4 and 3,4 structures increased (cis-1,4, 26-28\% and 3,4,8-23\%). ${ }^{1} \mathrm{~A}$ negative charge is localized at the $\alpha$-carbon and the phenyl ring on the living anion chain end of 1-PB, and its delocalization toward the $\gamma$-carbon is small. ${ }^{3}$ We attribute this negative charge distribution to electron withdrawing caused by the resonance effect of the phenyl group of 1-PB.

In this paper, the effects of the methoxy groups introduced at the para or ortho position of the phenyl ring of 1-PB are investigated. There have been many studies on $o-, m$, or $p$-methoxystyrenes. $^{5-8}$ The anionic polymerization of $o$ methoxystyrene has been reported to give high isotactic polymer. ${ }^{8}$ In this study, trans-1-(4-methoxyphenyl)-1,3-butadiene( $p$-MeO-1-PB) and trans-1(2-methoxyphenyl)-1,3-butadiene(o-MeO-1-PB) are synthesized and polymerized with $t$-BuLi. The microstructures of the resulting polymers and the negative charge distribution on the living anion chain end are investigated by NMR spectroscopies.

\section{EXPERIMENTAL}

The general experimental procedures have been described in previous papers. ${ }^{1,3}$ 
Table I. Anionic polymerization of $p-\mathrm{MeO}-1-\mathrm{PB}$

\begin{tabular}{|c|c|c|c|c|c|c|c|c|}
\hline \multirow{2}{*}{ No. } & \multirow{2}{*}{ Initiator } & \multirow{2}{*}{ Solvent } & \multirow{2}{*}{$\frac{\text { Temp }}{{ }^{\circ} \mathrm{C}}$} & \multirow{2}{*}{$\frac{\text { Conversion }}{\%}$} & \multicolumn{3}{|c|}{ Microstructure $/ \%$} & \multirow{2}{*}{$\frac{\text { Olefin } \mathrm{H} \text { found }^{\mathrm{b}}}{\%}$} \\
\hline & & & & & trans $-1,4$ & $c i s-1,4$ & 3,4 & \\
\hline 1 & $\mathrm{Na}-\mathrm{Naph}^{\mathrm{a}}$ & THF & 0 & 98 & 78 & 12 & 10 & 100 \\
\hline 2 & $t-\mathrm{BuLi}$ & THF & -78 & 94 & 79 & 11 & 10 & 100 \\
\hline 3 & $t$-BuLi & $\mathrm{THF}$ & 0 & 90 & 79 & 11 & 10 & 100 \\
\hline 4 & $t$-BuLi & Toluene & 0 & 74 & - & - & $>98$ & 74 \\
\hline 5 & $t-\mathrm{BuLi}$ & Toluene & 20 & 88 & - & - & $>98$ & 68 \\
\hline 6 & $t-\mathrm{BuLi}$ & Benzene & 20 & 85 & - & - & $>98$ & 79 \\
\hline
\end{tabular}

a Sodium naphthalene.

b Estimated by ${ }^{1} \mathrm{H}$ NMR spectra.

\section{Material}

$p$-MeO-1-PB and $o$-MeO-1-PB were prepared fom trans-4-methoxycinnamaldehyde and trans-2methoxycinnamaldehyde respectively by the procedure described in the literature, ${ }^{9}$ and purified by distillation over $\mathrm{LiAlH}_{4}$. trans-4-Methoxycinnamaldehyde and trans-2-methoxycinnamaldehyde were synthesized from $p$ - and $o$-anisaldehyde by the method in the literature. ${ }^{10}$. $t$ - BuLi was prepared by the method of $\mathrm{Smith}^{11}$ using $\mathrm{Li}$ dispersion (Alfa, $2 \%$ sodium).

\section{Polymerization Procedure}

Polymerization was carried out in a three-necked flask under a pure argon atmosphere.

\section{Oligomerization Procedure}

The oligomerization of $p-\mathrm{MeO}-1-\mathrm{PB}$ and $o-\mathrm{MeO}-$ 1-PB were carried out in ${ }^{13} \mathrm{C}$ NMR sample tube $(10 \mathrm{~mm} \phi)$ in situ under argon atmosphere with $t$ BuLi at $5^{\circ} \mathrm{C}$ for $1.5 \mathrm{~h}$; [monomer] $=0.59 \mathrm{~mol} \mathrm{dm}^{-3}$, $[t$-BuLi] $] /[$ monomer $]=1.5$. $p-\mathrm{MeO}-1-\mathrm{PB}$ and $o-\mathrm{MeO}-$ $1-\mathrm{PB}$ were used as toluene solutions $(50 \% \mathrm{w} / \mathrm{w})$.

\section{NMR spectra}

${ }^{13} \mathrm{C}$ and ${ }^{1} \mathrm{H}$ NMR spectra were recorded by a JEOL JNM FX100 spectrometer $\left(25.0 \mathrm{MHz}\right.$ for ${ }^{13} \mathrm{C}$ and $99.6 \mathrm{MHz}$ for ${ }^{1} \mathrm{H}$ ). Conditions for the measurements are described in a previous paper. ${ }^{3}$

\section{RESULTS AND DISCUSSION}

The results of the polymerization of $p$-MeO-1-PB are summarized in Table I. The results of elementary analyses of the polymers in this study agree with theoretical values. The typical ${ }^{13} \mathrm{C}$ NMR spec- tra of the polymer No. 2 and No. 6 are shown in Figure $1 \mathrm{~A}$ and $\mathrm{B}$. The spectrum appearing in Figure $1 \mathrm{~A}$ is almost identical to that of 1,4-poly(1-PB) prepared under the same conditions as that of sample No. 2, except that there is the appearance of the resonance of methoxy carbon (at $55.1 \mathrm{ppm}$ ) and the resonances of para and meta carbons shift to lower and higher fields respectively. Assignment of these resonances was carried out following that of 1,4-poly(1-PB) previously reported. ${ }^{1}$ The microstructures of the polymers were estimated from the relative intensities of the aliphatic carbon resonances and are listed in Table $\mathrm{I}$. The dyad sequence distributions in the samples No. 1, No. 2, and No. 3, estimated from the aliphatic carbon resonances, are identical to that of poly(1-PB) prepared under the same conditions. Figure 1B shows the spectrum of the sample No. 6 polymerized in benzene as the solvent. Poly(1-PB) obtained under the same condition as sample No. 6 , has predominantly a 1,4 structure and gives the ${ }^{13} \mathrm{C}$ NMR spectra similar to that in Figure 1A. On the other hand, the spectrum of Figure $1 \mathrm{~B}$ is quite different from this and is very similar to that of 3,4-poly(1-PB) which can be obtained with a Ziegler type catalyst, ${ }^{1}$ except that the methoxy carbon resonance appears and the resonances of para and meta carbons shift to lower and higher fields, respectively. In the spectrum, the resonances of the aliphatic region have humps, indicating that the 3,4 structure is contaminated by some irregular portions. ${ }^{*}$ The ${ }^{1} \mathrm{H}$ NMR spectrum

\footnotetext{
* This samples is considered not to contain the 1,4 unit and cyclized 1,4 unit since such structures must have ${ }^{13} \mathrm{C}$ resonances at a field lower than $48 \mathrm{ppm}$ according to the data of 1,4-poly(1-PB) and hydrogenated, 1,4-poly(1PB). ${ }^{12}$
} 


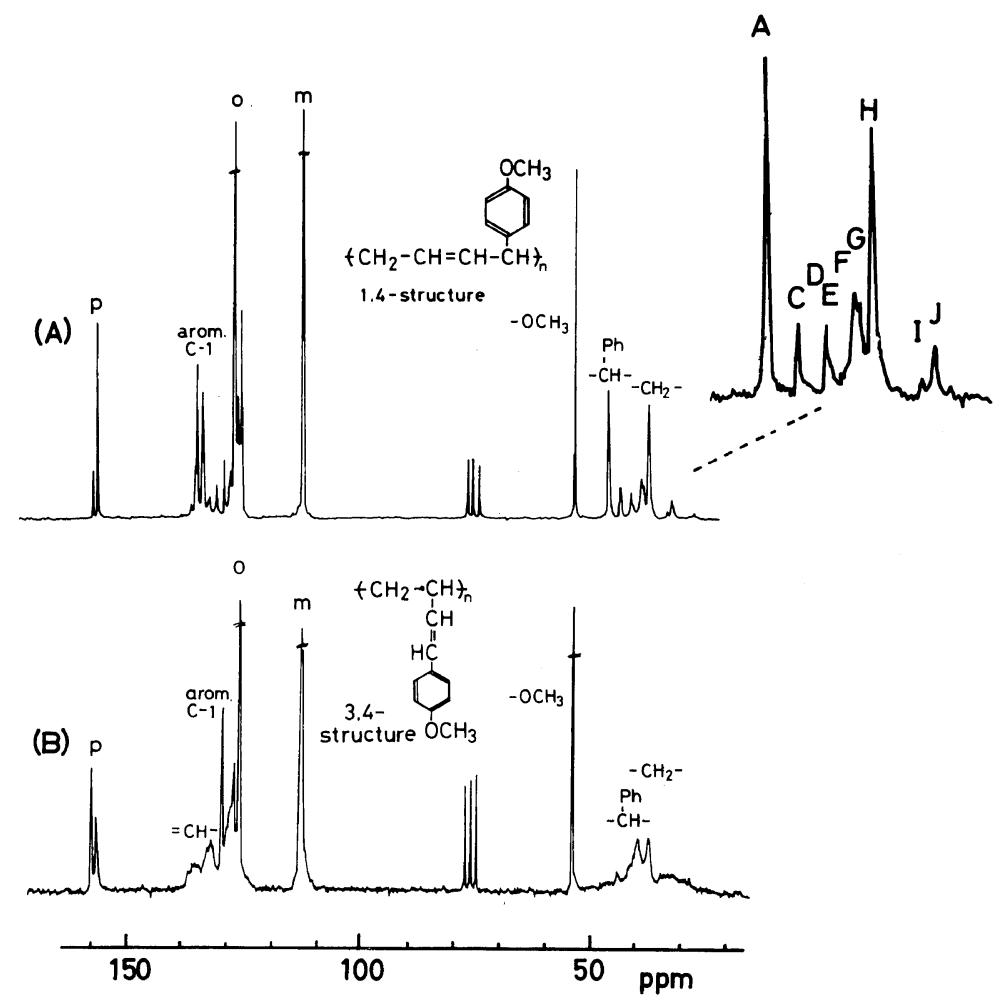

Figure 1. ${ }^{13} \mathrm{C}$ NMR spectra of poly ( $p$-MeO-1-PB): (A) sample No. 2 and (B) sample No. 6; designations of resonances in (A) correspond to those in Figure 5 and Table III of ref 1.

Table II. Anionic polymerization of $o-\mathrm{MeO}-1-\mathrm{PB}$

\begin{tabular}{|c|c|c|c|c|c|c|c|c|}
\hline \multirow{2}{*}{ No. } & \multirow{2}{*}{ Initiator } & \multirow{2}{*}{ Solvent } & \multirow{2}{*}{$\frac{\text { Temp }}{{ }^{\circ} \mathrm{C}}$} & \multirow{2}{*}{$\frac{\text { Conversion }}{\%}$} & \multicolumn{3}{|c|}{ Microstructure $/ \%$} & \multirow{2}{*}{$\frac{{\text { Olefin } \mathbf{H} \text { found }^{\mathrm{b}}}_{\%}}{\%}$} \\
\hline & & & & & trans $-1,4$ & cis-1,4 & 3,4 & \\
\hline 7 & $\mathrm{Na}-\mathrm{Naph}^{\mathrm{a}}$ & THF & 0 & 93 & - & - & $>98$ & 100 \\
\hline 8 & $t$-BuLi & THF & -78 & 59 & - & - & $>98$ & 100 \\
\hline 9 & $t-\mathrm{BuLi}$ & $\mathrm{THF}$ & 0 & 85 & - & - & $>98$ & 100 \\
\hline 10 & $t-\mathrm{BuLi}$ & Toluene & 0 & 27 & - & - & $>98$ & 37 \\
\hline 11 & $t-\mathrm{BuLi}$ & Toluene & 20 & 51 & - & - & $>98$ & 23 \\
\hline
\end{tabular}

a Sodium naphthalene.

b Estimated by ${ }^{1} \mathrm{H}$ NMR spectra.

of this sample clearly indicates that the ratio of the olefin protons to the phenyl protons is significantly less than two to five. The broader nature of the ${ }^{13} \mathrm{C}$ NMR spectrum thus can be due to the cyclization of 3,4 double bond.

The microstructure of poly $(p-\mathrm{MeO}-1-\mathrm{PB})$ estimated from the ${ }^{13} \mathrm{C}$ and ${ }^{1} \mathrm{H}$ NMR spectra are listed in
Table I. The polymer samples obtained in THF have mainly the trans- 1,4 structure and are almost identical in structure with poly(1-PB) prepared under the same conditions. On the other hand, the polymer samples obtained in toluene or benzene have very different structures from poly(1-PB) polymerized under the same conditions, and contain more than 


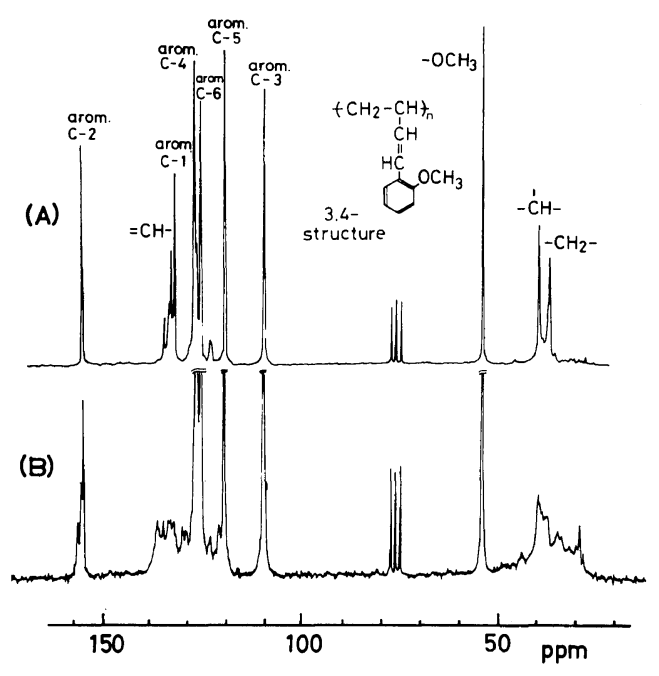

Figure 2. ${ }^{13} \mathrm{C}$ NMR spectra of poly $(o-\mathrm{MeO}-1-\mathrm{PB})$ : (A) sample No. 8 and (B) sample No. 10.

$98 \%$ of the 3,4 structure with cyclization. Thus the microstructure of poly ( $p$-MeO-1-PB) strongly depends on the polymerization solvent although that of poly(1-PB) is only slightly affected by this.

The results of the polymerizations of $o-\mathrm{MeO}-1$ $\mathrm{PB}$ are summarized in Table II and the typical ${ }^{13} \mathrm{C}$ NMR spectra of the polymers are shown in Figure 2. The spectrum of the sample No. 8 obtained in THF is shown in Figure 2A. The aliphatic region of this spectrum is quite different from 1,4-poly(1-PB) polymerized under the same conditions and nearly identical with that of 3,4-poly(1-PB). Figure 2B shows the spectrum of sample No. 10. This spectrum is very complicated, indicating that the double bond of the 3,4 unit is cyclized to a considerable extent. The proportion of the cyclization was estimated from the ${ }^{1} \mathrm{H}$ NMR spectrum.

The microstructures of poly $(o-\mathrm{Me}-1-\mathrm{PB})$ estimated by ${ }^{13} \mathrm{C}$ and ${ }^{1} \mathrm{H}$ NMR spectra are listed in Table II. The polymer samples obtained in THF have more than $98 \%$ of the 3,4 structure regardless of counter cations and the polymerization temperature. On the other hand, polymer samples polymerized in toluene also have the 3,4 structure. However, in these cases, a considerable number of 3,4 units is consumed by the cyclization. The substitution of the methoxy group at the ortho position of 1-PB greatly changes the microstructure of the polymer prepared by anionic initiators. Cyclizations
Table III. ${ }^{13} \mathrm{C}$ chemical shift and $\pi$-electron density for living oligomeric $p$-MeO-1-PB and $o$-MeO-1-PB

\begin{tabular}{|c|c|c|c|c|}
\hline \multirow{2}{*}{ Position } & \multicolumn{2}{|c|}{$p$-MeO-1-PB } & \multicolumn{2}{|c|}{$o-\mathrm{MeO}-1-\mathrm{PB}$} \\
\hline & $\delta^{\mathrm{a}}$ & $\rho^{\mathbf{b}}$ & $\delta$ & $\rho$ \\
\hline$\alpha$ & $\begin{array}{l}65.6 \\
66.3\end{array}$ & $\begin{array}{l}1.43 \\
1.43\end{array}$ & 62.6 & 1.45 \\
\hline$\beta$ & 135.9 & 0.98 & 135.2 & 0.99 \\
\hline$\gamma$ & $\begin{array}{l}84.6^{C} \\
85.2\end{array}$ & $\begin{array}{l}1.31 \\
1.31\end{array}$ & 92.0 & 1.26 \\
\hline$\delta$ & 51.0 & - & 50.7 & - \\
\hline $\begin{array}{l}\text { Arom. } \\
\text { C-1 }\end{array}$ & $\begin{array}{l}144.6 \\
144.5\end{array}$ & $\begin{array}{l}0.93 \\
0.93\end{array}$ & 139.3 & 0.96 \\
\hline $\mathrm{C}-2$ & $\begin{array}{l}116.2 \\
115.8\end{array}$ & $\begin{array}{l}1.11 \\
1.11\end{array}$ & 148.4 & 0.90 \\
\hline $\mathrm{C}-3$ & $\begin{array}{l}116.7 \\
116.2\end{array}$ & $\begin{array}{l}1.11 \\
1.11\end{array}$ & 112.5 & 1.13 \\
\hline C-4 & 147.5 & 0.91 & 104.4 & 1.18 \\
\hline C-5 & \multicolumn{2}{|c|}{ Same as C-3 } & 123.4 & 1.06 \\
\hline C-6 & Same a & $C-4$ & 111.8 & 1.14 \\
\hline
\end{tabular}

a Chemical shift in ppm downfield from TMS using the solvent peak as standard; THF 67.0.

b $\pi$-electron density calculated by the following equation $^{13} ; \delta=289.5-156.3 \rho$.

c A set of data shows the cis isomer above and the trans isomer below.

of the 3,4-polymer through double bonds at the side chain were observed when polymerization was carried out in hydrocarbon media.

In order to study the effect of the substitution of the methoxy group further, ${ }^{13} \mathrm{C}$ NMR spectra of the living anion chain ends of oligomeric $p$-MeO-1-PB and $o$-MeO-1-PB were investigated. Figure 3A shows the ${ }^{13} \mathrm{C}$ NMR spectrum of the living anion chain ends of oligomeric $p$-MeO-1-PB in THF. In this spectrum, the resonances designated as $\alpha, \beta, \gamma$, ortho $(o)$, meta $(m)$, para $(p)$, and the aromatic C-1 (arom. C-1) of the living chain end appear. The chemical shifts of the resonances are listed in Table III along with the $\pi$-electron densities calculated by 


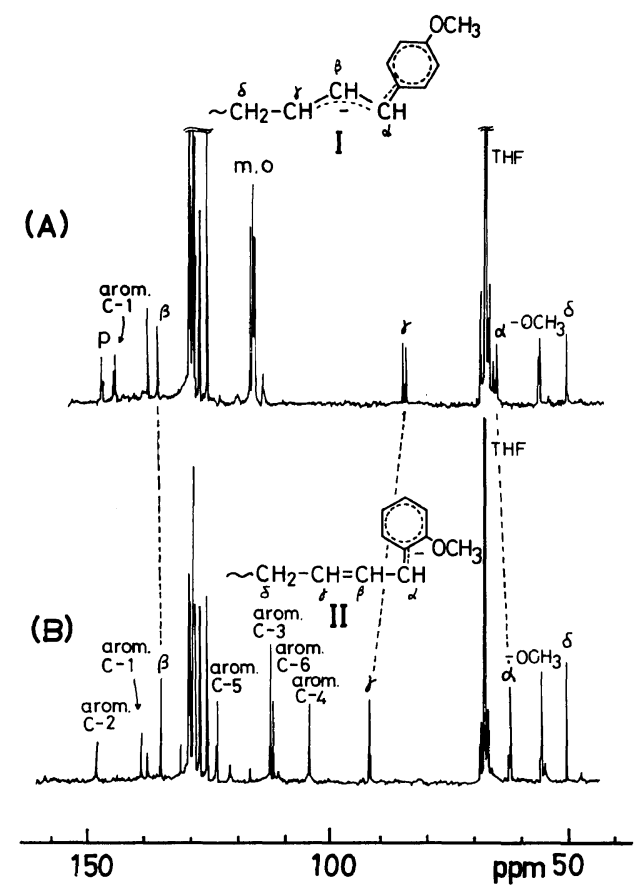

Figure 3. ${ }^{13} \mathrm{C}$ NMR spectra of living anion chain ends of (A) oligomeric $p$-MeO-1-PB $(D P=1.4)$ and (B) oligomeric $o$-MeO-1-PB $(D P=1.1) ; D P$ is determined with GPC after protonation of the anion.

O'Brien's equation with the ${ }^{13} \mathrm{C}$ chemical shifts. ${ }^{11}$ Among these, the resonances of the $\gamma$ and $\alpha$ carbons shifted by 5 and $2 \mathrm{ppm}$ to a higher field respectively as compared with the corresponding carbon resonances of oligomeric living 1-PB chain end. These shifts are attributed to the change in the negative charge distribution caused by the methoxy group at the para position. The electron-releasing methoxy group pushes a portion of the negative charge out of the phenyl ring onto the $\alpha$ and $\gamma$ carbons in the living anion chain end. Since the amount of the high field shift of the $\gamma$-carbon is larger than that of the $\alpha$-carbon, the spectrum suggests that the anion is mainly composed of the $\pi$ allylphenyl type chain end shown in I in Figure 3. Such a charge-delocalized chain end favors the inchain 3,4 unit since the monomer is liable to attack the $\gamma$-carbon. However, polymer samples prepared in THF have low 3,4 content as shown above. Such small change in the negative charge distribution may not affect the microstructure of the resulting polymer. The resonances of the $\gamma, \alpha$, and methoxy carbons consist of two peaks of almost equal intensity, indicating the chain end is a mixture of nearly equal amounts of trans- 4,1 and $c i s-4,1$ chain ends. However, the in-chain unit is a predominantly trans-1,4 structure, as shown above. When the polymerization was carried out in toluene or benzene, the polymer has a 3,4 structure whose double bond is considerably consumed by cyclization. Unfortunately, the living anion chain end could not be observed by the NMR spectroscopies in hydrocarbon media because of the poor solubility of the living oligomer. The living oligomeric $p$-MeO-1PB could be solubilized in hydrocarbon media (benzene or toluene) when the DP (degree of polymerization) of the oligomer extended to 5 . However, no resonance of the anion chain end could be observed by NMR spectroscopy, although the in-chain resonances appeared. The anion chain end is considered highly aggregated in many different manners and consequently the resonances of the living chain ends are very broad. The drastic change in the microstructure observed with poly $(p-\mathrm{MeO}-1$ PB) obtained in hydrocarbon media may possibly be attributed to the highly aggregated chain end structure caused by the intermolecular coordination of the methoxy oxygen with the lithium cation. The monomer cannot approach the $\alpha$-carbon due to the crowded strucrture at the $\alpha$-position. Therefore, the monomer attacks the $\gamma$-carbon to give the high 3,4 content. In a THF medium, such an aggregation cannot occur and the resulting polymers have low 3,4 content.

Figure $3 \mathrm{~B}$ shows the ${ }^{13} \mathrm{C}$ NMR spectrum of the living chain end of oligomeric $o$-MeO-1-PB in THF. In the spectrum, $\alpha, \beta, \gamma$, and the aromatic carbon resonances of the living anion chain end appear. The chemical shifts of the resonances are listed in Table III as well as the $\pi$-electron densities. The resonance of the $\gamma$-carbon shifted by 2 ppm to a lower field and that of the $\alpha$-carbon shifted by $5 \mathrm{ppm}$ to a higher field as compared with the corresponding carbon resonances of the living oligomeric 1-PB chain end. This shows that the electron density of the $\alpha$-carbon increased and that of the $\gamma$-carbon decreased with the introduction of the methoxy substituent into the ortho position. This means that the living chain end rather approximates the $\pi$-benzyl type chain end shown in II in Figure 3. This chain end favors the in-chain 1,4 structure since the reactivity of the $\alpha$ carbon is higher. However, the polymers prepared 


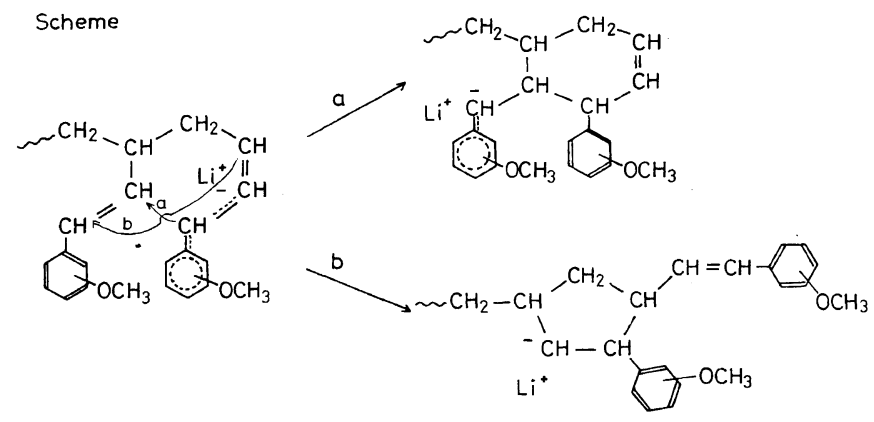

in both THF and toluene contain only the 3,4 structure. The steric hindrance caused by the ortho methoxy group must surely affect the microstructures. The monomer cannot attack the $\alpha$-carbon because of the steric hindrance of the ortho methoxy group and this results in the in-chain 3,4 structure. Unfortunately, again in the hydrocarbon media, the living anion chain end of $o-\mathrm{MeO}-1-\mathrm{PB}$ could not be observed by NMR spectroscopy because of the poor solubility of the anion. The living oligomer could be solubilized when $D P$ of the oligomer was extended to 3. However, no resonance of the anion chain end could be observed by the NMR spectroscopies, but in-chain resonances appeared. In the hydrocarbon media, the living anion chain end seems highly aggregated in the same way as in the case of $p$-MeO-1-PB. The aggregated chain end structure as well as the steric hindrance caused by the ortho methoxy group determine the microstructure, giving 3,4 polymers.

In this way the negative charge distribution of the chain ends cannot be used to interpret the changes in the microstructures of $\operatorname{poly}(p-\mathrm{MeO}-1-\mathrm{PB})$ and poly $(o-\mathrm{Meo}-1-\mathrm{PB})$. The microstructures of the resulting polymers are determined by the aggregated structures of the chain ends or the steric hindrance caused by the ortho methoxy group, except for the polymerization of $p$-MeO-1-PB in THF. These factors could not be evaluated by NMR spectroscopic methods.

In polymerization in hydrocarbon media, cyclizations of the 3,4 double bonds occur to a considerable extent. These cyclizations seem to be related to the aggregated chain ends. Such sterically crowded chain ends rather attack the in-chain 3,4 double bond rather than the monomers (back biting). The cyclizations are considered to occur intramolecularly since the molecular weights of the cyclized polymers do not increase as compared with noncyclized samples (about 10,000). The sample of the cyclization mechanism is proposed in the Scheme.

\section{REFERENCES}

1. T. Suzuki, Y. Tsuji, and Y. Takegami, Macromolecules, 11, 639 (1978).

2. T. Suzuki, Y. Tsuji, Y. Takegami, and H. J. Harwood, Macromolecules, 12, 234 (1979).

3. T. Suzuki, Y. Tsuji, Y. Watanabe, and Y. Takegami, Polym. J., 11, 651 (1979).

4. T. Suzuki, Y. Tsuji, Y. Watanabe, and Y. Takegami, Polym. J., 11, 937 (1979).

5. Y. Imanishi, S. Matsushita, T. Higashimura, and S. Okamura, Makromol. Chem., 70, 68 (1964).

6. Y. Ohsumi, S. Tani, T. Higashimura, and S. Okamura, J. Macromol. Sci., Chem., 2, 727 (1968).

7. G. Natta, G. Dall'Asta, G. Mazzanti, and A. Casale, Makromol. Chem., 58, 217 (1962).

8. H. Yuki, Y. Okamoto, Y. Kuwae, and K. Hatada, J. Polym. Sci., A-1, 7, 1933 (1969).

9. E. I. Becker, "Organic Syntheses," Collect. Vol. IV, Wiley, New York, N.Y., 1963, p 771.

10. K. Friedrich and W. Hartmann, Berichte., 94, 838 (1961).

11. W. N. Smith, Jr., J. Organomet. Chem., 82, 1 (1974).

12. T. Suzuki, Y. Tsuji, Y. Watanabe, and Y. Takegami, Macromolecules, 13, 849 (1980).

13. D. H. O'Brien, A. J. Hart, and C. R. Russel, J. Am. Chem. Soc., 97, 4410 (1975). 